\title{
RECENT EXPERIMENTS IN THE CONTROL OF TWO PUERTO RICAN ANTS
}

By George N. WoLcotw, Entomologist, Insular Experiment Station, Río Piedras, P. R.

The control of ants in temperate zones is a comparatively simple matter, for ants there affect man directly mostly as household pests (and to only a minor degree in decreasing crop production), and against them in houses, simple and familiar methods of control have long been in use. As a natural consequence, comparatively little attention has been given to devising any new remedies. When a foreign ant, such as the so-called Argentine Ant, with most injurious habits, and not susceptible to the time-worn and "old reliable" methods of control, does become established, adequate study of its habits and individual preferences eventually shows how it may be controlled (1). A comparable result may be confidently anticipated in the tropics when the importance of the various economic species is recognized and the control of each is considered a separate and distinct problem. To be sure, numerous species of ants are household pests in the tropies, but some of the same, or often quite different species are of much greater importance as factors in affecting crop production. Their habits are often, in the main, similar to those of the ants of temperate zones, but in other cases are so completely different that they are only slightly inconvenienced if the methods of control so successfully used elsewhere against other species are tried out against them. Even, and in many cases especially, the Argentine Ant syrup-devised for use against this one ant and against no other-is a failure. The fundamental difficulty is that the most diverse of tropical ants are lumped together as one kind of insect, against which one standardized method of control should be effective. As a matter of fact, they are as different and individual in their habits as tho they belonged to different orders of insects. In Puerto Rico, the country people speak of and recognize several kinds of ants, and most of them know at least the following:

1. "albaricoque", Tapinoma melanocephala F.

2. "albayalde", Wasmannia auropunctata Roger.

3. "barraco", Odontomachus haematodes L.

4. "hormiga brava", Solenopsis geminata F.

5. "hormiga loca", Prenolepsis longicornis Latreille.

6. "hormiguilla", Myrmelachista ambigua ramulorum Wheeler. 
To be sure, this is hardly more than a tenth of the total number of kinds of ants found here by Dr. Wheeler (2), but it includes all the common and distinctive species. That so many can be distinguished by an ordinary person is the surest indication that in their activities, or some other factor affecting man, they are essentially and fundamentally different.

Of all the species of ants present in Puerto Rico, the fire ant or "hormiga brava" is by far the most abundant generally, and affects man in the most varied ways. It is a pest in citrus groves and in pineapple plantations, and as these crops earliest received attention at the newly organized Agricultural Experiment Station at Mayagüez, the first economic study of the hormiga brava in Puerto Rico was conducted there (3). The slender circular (undated and with not even the place of publication noted) detailing the results of these studies has long been out of print. Because the method of control there given is today just as effective and practical as when first devised, it is here reprinted without change. It should be noted, however, that the common mealybug of pineapples, in Puerto Rico as elsewhere, is Pseudococcus brevipes Cockerell.

\title{
PORTO RICO AGRICULTURAL EXPERIMENT STATION
}

D. W. MAx, Special Agent in Charge

Circular No. 7

\author{
Control of the Brown AnT \\ (Solenopsis geminata, Fab.) \\ and the \\ MenLy Bug \\ (Pseudococcus citri, Risso)
}

IN PINEAPPLE PLANTATIONS .

The brown ant and the mealy bug are at present doing considerable damage to pineapples. The brown ant alone seldom does any real damage; it is when it accompanies the mealy bug that the destructive work begins.

These ants are always found where mealy bugs are present, not eating the plants themselves, but attending the mealy bugs, earrying them from place to place, distributing them over the new leaves, and, as a reward for their labor, obtaining the honey dew which is secreted by the mealy bug. A few eases have been observed where the mealy bugs were so numerous that they irritated the fruit to such an extent that the juice began to run. This was eaten by the ants and they then continued to eat into the fruit, puncturing it and getting more of the juice. Some of these fruits were packed and shipped to New York, while others were kept at the Station. The fruits shipped to New York broke down and were unsalable. On examining a number of fruits after ten days, which is equal to the time elapsed in shipping, it was found that a fungus had gained entrance through these minute holes, eausing the pines to break down. 


\section{LOCATION OF ANTS' NESTS}

Ants generally attack the outer rows of plants first, gradually working in towards the center of the patch. The outer rows and borders of a pineapple field should be carefully watched and all ant hills destroyed as soon as found.

The nests of the brown ant are found in almost any part of the pineapple plantation; around the base of the plants, under the roots between the rows and in the paths, but more often they are found around the roots of the plant. When the nest is under the plant, the ants often carry sand and earth up into the plants and build other nests in leaf axils.

Upon examining these nests a great many mealy bugs are to be found. These are tended by the ants and distributed by them over the young leaves, and from plant to plant.

Before the flower stalk develops, the mealy bugs are found on the leaves around the center of the plant, especially between young leaves which are very close together, as these afford better protection for the insect. On fruiting plants, the mealy bugs are found on the flower stalk, also around the base of the fruit, and very often on the fruit itself.

\section{NOTES ON SPRAYING}

Kerosene emulsion, with a small amount of crude carbolic acid has given the most satisfactory results in killing the mealy bugs and the ants. Extensive tests with crude oil sprays have been made but none of these emulsions have proved as effective in killing the ants and mealy bugs as emulsions made with a low grade of kerosene oil and crude carbolic acid.

Formula for Spraying Pineapples.

2 gallons of kerosene

1 pint of crude carbolic acid

$1 / 2$ pound Fairbank's Blue Cloud Soap, or Good Caustic Potash Soap.

1 gallon of water

First put the oil in a barrel. Then dissolve the soap in the water with the carbolic acid by boiling, and pour into the barrel. Mix the whole with a spray pump by pumping back into the barrel for half an hour. A creamy mixture will be obtained which should hold up for from two to three weeks. This is to be used as a stock emulsion. Use 1 gallon of stock emulsion to 8 gallons of water.

\section{ANTS' NESTS UNDER PLANTS}

When there is an ants' nest directly under and around the plant, it is best to spray the nest first. If this is not done, the first drops of spray falling from the plant will startle the ants and they will immediately begin to move out carrying their young with them, and in this way many will escape the spray. When the nest is large, it is suggested that it be sprayed and then broken up with the nozzle forcing the spray down into the nest. In this way few ants have a chance to escape, but, as many of them are away feeding at the time, it is necessary to spray again the next day when the remaining ants will be busy building a new nest. This new nest is built close to the old one. All nests in the paths and between banks should be treated in the above manner.

An extension rod about three feet long is very handy in spraying pines, and an elbow is also advised so that the spray may readily be turned down between the leaves. 
There is a time in the life of the pineapple plant when it should not be sprayed, that is, when the fruit bud is forming. At this time the bud is very delicate and any spray which will lijl the mealy bug or ant, is liable to injure the bud. The spray does not always kill the blossom, but the fruit may develop without a top or erown. Fruits which have formed and stopped blossoming may be sprayed, but great care should be taken.

As the mealy bug is found between the central or the new leaves of the pine, a nozzle which throws a fine but foreible spray is ideal. The nozzle should not throw a spray which spreads over a great area, but one which ean be directed down between the leaves, reaching a depth of eight inches and not spreading over an area of more than four incles. It is not the amount of spray that kills, but the spray that hits the mealy bug with force enough to remove the mealy coat and thus saturate the skin of the insect.

As the heart leaves of a pineapple are very small and lay very elose to the next set of leaves, it is recommended that the nozzle be placed against one of the second row of leaves, thus spraying the outside of the heart leaf and the inside of the next leaf at the sale time. There are generally three sets of these leaves which come together in the above mamer. It may seem impracticable to spray in this way, but, if the nozzle is not inserted between the heart leaves, the mealy bug will not be killed. To spray in this way takes a little longer than filling the crown, but after one has become accustomed to the work, it ean be done very quiekly.

When pines are sprayed in this mamer the enulsion runs down over the central portion of the plant, filling up the crown and gradually running down around the roots.

\section{W. V. TOWER, Entomologist.}

Mr. Tower, continuing his observation on the hormiga brava as it affected citrus growing (4), states that on fruits, "the scars made by ants are altogether different from those produced by the wind, the former being deep-seated and caused by the insects removing some of the epidermis and eating into the fruit.

"There are several species of ants which feed upon the nectar secreted by the orange blossoms. The brown ant and the little black ant are especially fond of the nectar. These two species have been seen working in the blossoms in the early morning, sipping the nectar, and toward noon, when it has been exhausted, attacking the unopened blossoms, or young fruit. Some eases have been observed where the green calyx leaves were eaten so badly that the fruit dropped. In other cases the pistil was chewed off and the fruit never developed. Again, the brown ant sometimes cuts holes in the young fruit.

"Ants do more damage during years when there is seanty bloom or when the bloom extends over a prolonged period, as they eat the fruit when not supplied with sufficient neetar. 
quickly rot the rubber gaskets and other rubber parts of the spraying apparatus coming in direct contact with the spray. In other respects, however, crude carbolic acid meets every requirement, for it is cheap, easy to apply and unquestionably effective in lilling ants. In the case of many insecticides, a purer or finer (and more expensive) grade of poison is necessary if injury to the plant is to be avoided, but in the case of carbolic acid, the effectiveness resides largely in crudities present with the acid. Consequently, the dark, unpurified and cheapest grades (containing the smallest amounts of carbolic acid) are the most desirable for insecticidal purposes.

A little later, when commercial manufacturers began placing oil emulsions or "miscible oils" on the market which were equally effective in killing scale, and much easier to use because they need only to be diluted with water, many growers ceased to make up their own sprays and relied entirely on the commercial product. Some of these contained some crude carbolic acid, added by the manufacturer for ease in making the emulsion and not for any insecticidal value the substance might have, but others contained none. No stress was laid on whether the product did, or did not, contain enough crude carbolic acid to kill ants, and in general, most growers did not consider this factor in making their selection from the numerous products recommended primarily (and usually solely) for killing scales. Of course, most groves on the Island are mature and established now, and suffer less noticeable ant injury; but in nurseries and young groves ants are no less abundant or injurious than they have been formerly, and the need for a means of control is just as great as ever. Theoretically, the problem of control of hormiga brava by means of crude carbolic acid emulsion is solved; practically, from the standpoint of large growers who no longer make up their own spray concentrates, it is not.

Of the poisons which have come into more general use since the war, the one which has been used with the greatest success in ant control is thallium sulfate. Considerable newspaper publicity at the time was given to successful demonstrations in destroying ants by means of a thallium syrup, conducted in the White House by Dr. R. T. Cotton, formerly of this Station. He furnished a small amount of this expensive and most virulent poison for conducting experiments in the control of the hormiga brava in Puerto Rico. His methods (5) were followed exactly at first, using the formula of onefourteenth of an ounce of thallium sulfate dissolved by boiling in a pint of water, to which is added a pound of sugar and three ounces of honey. A trial was made of the paraffined pill boxes which he 
had found useful as containers for the syrup. These containers serve reasonably well in houses, if not disturbed by children, pets or servants, but out-of-doors in citrus groves, they quickly go to pieces. The experiments were continued with paraffined paper cups, all of one piece of tougher paper, over which a cap fits, manufactured especially for this purpuse by the Antrol Laboratories of Los Angeles. Such cups were used in all later experiments and were much more satisfactory. The experiments were conducted in the small citrus grove back of the Sub-Station building at Isabela, and in lawns and flower gardens near-by. In all cases, the ants appeared to feed on the syrup at first, but so far as one could judge, were but little affected by it, and soon learned to avoid it entirely. The results were uniformly discouraging, for in no case was even a small colony of ants completely destroyed, and no apparent impression was made on larger colonies. If the cup was placed at the entrance of the nest, the ants constructed a new entrance several feet away. If a fresh cup was placed at the new entrance, this also was deserted. One large colony in a lawn construeted six new entrances thus in succession, and while some of the ants may have been killed by the poison, no permanent reduction in their numbers was observable. If the cup was placed at the base of a eitrus tree, where the ants were ascending and descending, they soon moved their line of march so as to avoid coming near the cup, and if another cup was placed in the new line of march, this also the ants soon learned to avoid. A final and definite experiment planned in the citrus grove at Isabela, laid out at the time of the experimenter's departure, appeared to be a complete success, when examined about two months later. This apparent success was entirely due, however, to the trees and nests having been sprayed by the mayordomo with crude carbolic acid emulsion a few days previous to examination. He had given up hope of the thallium syrup having any effect, and was determined to save the trees from ant injury by a method of the efficiency of which he had been convinced by demonstration on the main block of trees.

In most marked contrast of the uniform failure of thallium out of doors, the syrup was most unexpectedly successful when used in the house, and has sinee proved uniformly valuable in every experiment since conducted. A cup of syrup placed on the line of march of ants going from their nest to a garbage pail, food safe, bread box or refrigerator, will, within a few hours, eliminate them entirely from their chosen food, and in less than a day they will cease to visit the cup of poison syrup. Weeks later they may again return, but putting the cup out again on the line of march will disperse them more 
quickly than before. The syrup is of no value when placed with or beside the food, but when several feet nearer the nest than the food, works with almost magical effect. Collapsible tubes of this syrup can be purchased locally and can be recommended to housekeepers who are not interested in the home preparation of the poison syrup.

While these experiments were being conducted, reports of the successful use of this poison syrup in the citrus groves of the Río Grande Valley of south Texas were received (6), and Mr. C. H. Behse, Jr., of the Gulf States Chemical Co. of Harlingen, Texas, came to Puerto Rico to try out some of the mixtures which had proved so successful in south Texas. His experiments in the citrus. groves here were no more successful than those conducted by the writer, and as a result of their failure, he submitted additional mixtures, of varying composition, to be tested here. One of these was his standard dry pellets in a collapsible tube, another the syrup in a tube, a third a combination with dried blood, and a fourth, an unknown mixture, dark in color. All of these were placed at the base and higher up in the crotches of large citrus trees near the beach at Dorado, all trees being heavily infested with hormiga brava. After several weeks, they were replaced with fresh tubes. As the supply of tubes containing the unknown were exhausted, these were replaced with a mixture of thallium acetate and ground meat. In some cases, a possible diminution in the number of ants might be imagined on some of these trees, especially those on which the standard syrup was present, but in no case was it sufficiently marked to be considered as constituting even commercial control. After several months, additional fresh tubes and thallium acetate and meat were placed on the trees, but after the lapse of several more months, no more definite results consequent on the presence of the poison could be observed than before.

As a final conclusion to this poison experiment, to parallel a similar experiment previously conducted with the "hormiguilla", a mixture of Hamburg steak and sodium cyanide was placed at the check trees, which had not previously been treated with any poison. The action of the fresh meat on the cyanide is to cause the immediate liberation of hydrocyanic acid gas, which kills all the ants coming anywhere near the meat. Within a few minutes after application thousands of ants were killed, but some were still running about a few hours later, and when the trees were examined a few weeks later, some of the colonies appeared even larger than before. Before making a fresh application of meat and cyanide, all the loose sand at the base of the trees was brushed away, so that the meat could be placed 
in close contact with the base of the tree and no ants descending to their nest could avoid it. Within a few minutes thousands of ants were killed, and by moving the bits of meat about so that they rested beneath runways not at first eovered, all the ants in sight were soon killed. Brushing away still more of the sand and exposing some of the ants in the nest, these also were quickly killed by placing the meat in their midst. As an indication of how rapid was the action of the poison when properly applied, the case should be mentioned of one tree which had been densely over-run with hormiga brava tending cottony cushion scale. After a few minutes, it was so completely freed of ants that it could be ascended with safety, without danger of being bitten. Meat unmixed with cyanide is very attractive to hormiga brava, but no case was noted of the ants attempting to eat the poisoned meat. In this respect their action was very different from that of the "hormiguilla", a slow-moving, phlegmatic ant which remains quietly in one place eating the poisoned meat until overeome by the hydrocyanic acid fumes. The action of the cyanide and the meat rapidly destroys the great majority of the foraging workers, but some remain uninjured and unaffected deep in the ground. Thus the colony is greatly weakened, but not exterminated. It is not an especially cheap or simple method of killing ants, but it was some satisfaction to see some dead ants after vainly putting out thallium mixtures for so many months. Indeed, it is no more effective than dusting the nests with calcium cyanide dust, a much simpler method of obtaining the same result: the immediate destruction of the great majority of the ants.

The local agency handling the thallium tubes manufactured by Mr. Behse's company reported one rather considerable sale of them to a citrus grower near Barceloneta. He reported that his experience with them had been most successful, and his grove was visited to determine, if possible, the cause of his success. The tubes had been placed in a young grove after the ground between the trees had been thoroly cultivated in preparation for growing vegetables, and after the young trees had been thoroly sprayed, so that most of them were at least commercially free of scale. It is hardly surprising, therefore that after nine-tenths of the ant nests had been broken up by plowing and cultivation, and the main source of food for the ants (the honey dew from the soft scales on the citrus trees) removed, the few survivors had been destroyed by the poison bait. In every case where all the soft scales on a tree had not been killed by spraying, it was invariably heavily infested with ants, indicating that the successful results claimed for the poison were in reality largely due to starvatinn. 
The thallium tubes may be of some value in earefully cultivated and sprayed young groves, but they are really a minor factor in ant control. Even better results might much more easily and cheaply be attained by adding the requisite amount of crude carbolic acid to the oil emulsion spray used to kill the scale.

The "hormiguilla" or coffee shade tree ant, Myrmelachista ambigua ramulorum Wheeler, is a small ant with reddish-yellow thorax and blue-black head and abdomen that "nests in populous colonies in the hollow twigs of trees, especially the sea-grape and "torchuelo" (2), but in coffee groves it nests in the older guaba or guamá (Inga vera and Inga laurina) trees, and when these are heavily infested, it also attacks the coffee trees. The ants eat out irregular longitudinal tunnels in the main trunk and branches of the trees and seldom live in colonies in dead wood. In some compartments of their tunnels they rear their young, in others they care for mealbugs, Pseudococcus citri Risso, or the peculiar pink fleshy scale insects, Crytostigmo inquilina Newstead, that suck sap from the tree and secrete a honey-dew which is very attractive to the ants. The most noticeable outward indication that coffee trees show of their being infested with the hormiguilla is a peculiar swollen, warty growth of bark where the lateral branches join the main trunk. The tunnels of the hormiguilla are discontinuous and seldom of uniform size. Parts of the infested branches will be entirely uninjured, while in other places the tunnels will be so broad as to greatly weaken the trees, so that they are easily broken in storms or when the berries are being picked. The scale insects and the mealybugs which the ants care for and largely depend on for food, obtain their nourishment from the sap of the tree, and even a light infestation of the hormiguilla reduces the vitality of the coffee trees so that they produce only small crops. A heavy infestation kills the top branches, and very rarely the entire tree is killed. Most growers consider the hormiguilla the most serious and destructive insect pest in their groves.

The old guaba and guamá trees in a coffee grove are the centers from which the ants go out to establish other colonies in the coffee trees, and the destruction of these old trees and the planting of new shade will eliminate the hormiguilla for several years. The smoke of charcoal fires has no effect on the hormiguilla, except, naturally, that many ants perish when the trees in which they have been living are cut down and used in making charcoal.

But the eutting down of these old shade trees is not always practicable, and in such cases the number of hormiguilla nesting in them can be very considerably reduced by poisoning them. Because the 
hormiguilla has no one main nest, and because most of the ants remain within their tumnels in the tree most of the time, comparatively few are killed by a spray of earbolic acid emulsion, or by dusting -with calcium cyanicle. Altho the ants feed on the sweet excrement of their mealybugs and scale insects, they are not attracted by poisoned sweet substances prepared by man for their destruction. The Argentine Ant syrup they ignore entirely. But it was observed that they are attracted by dead insects and bird droppings that happen to occur on the leaves of infested trees, and when bits of meat; fish or cheese are placed on the trees, these are soon surrounded by ants feeding upon them. After numerous experiments with various kinds of poisons, it was discovered that potassium or sodium cyanide, powdered and mixed with meat would attract and kill the hormiguilla. The ants stay within their tumnels when it is rainy, and can not be enticed out even by fresh meat, and no poisoning should be attempted except during dry weather. At such times, a mixture of one pound of meat with two ounces of powdered sodium cyanide may be applied in the form of little shelves beneath the places where the ants are abundant, where the bark is rough or there are cuts in it to which the plastic mixture will adhere. The moisture and acid of the meat reacts on the poison to set free a very poisonous gas, hydroeyanic acid, which is lighter than air, and therefore kills only the ants that are above the little shelf. The gas acts on the ants promptly, but if they fall to the ground, they will eventually recover from its effects. But if the meat is placed in the form of a shelf so that the ants overcome by the poisonous fumes do not fall off but remain within its influence for even a few minutes longer, they will be dead.

During the years 1923-24 extensive experiments in this method of destroying the hormiguilla were conducted. Three applications of poisoned meat, at intervals of two or three days, killed practically all of the ants on a rather lightly infested guamá tree near Mayagïez. On three other trees, much more heavily infested, the same number of applications killed many more ants, but considerable numbers survived. An experiment was started in November and continued throughout the winter and spring on a large jagüey tree in the Ciales valley near Manati, which was heavily infested with hormiguilla. In all, eight applications (Nov. 5, Dec. 13, Dec. 28, Jan. 14, March 3, March 17, April 3 and April 8) of the poisoned meat were made, using a pound of meat and one or two ounces of poison for each application. Altho enormous numbers of ants were killed, and at each successive application the decrease in the ant population was noticeable, yet the applications were made at too great intervals 
for maximum effectiveness, and the tree was still somewhat infested at the time the last application was made.

As the experiment was continued, certain refinements of methods were adopted. By smearing the very smallest amount of unpoisoned. meat about half an inch above the point where the poisoned meat shelf was to be placed, the ants could be induced to collect there and be overcome by the fumes of poison rising from the shelf beneath. The hydrocyanic acid gas is generated in the greatest quantity in the first few minutes after the cyanide is mixed with the meat, and is most effective the more promptly it can be applied to the tree. It continues to be generated for several days, but in much smaller amounts after the first few hours. If the meat does not dry out, it is effective for a considerable period, and has been observed to kill ants five hours after application. Also, the poisoned meat begins to harden soon after mixing, and the more promptly it can be applied, the more easily it can be shaped into a shelf, and the better it sticks. Thus, during the later experiments, only half a pound of meat and an ounce of poison were mixed at a time, the second half pound being mixed and applied some time later. From one shelf, the dead ants were collected and found to number 2,400. If all the shelves were a: favorably located, and killing with this efficiency, the total number of ants killed on a large tree would be enormous. The ants killed should weigh almost as much as the meat, for their dead bodies pile up on the shelves so as to bulk larger than the shelves themselves, when not blown away by the wind.

This method of killing hormiguilla, despite the enormous numbers of ants killed, does not destroy the colony, and merely reduces the infestation. But their numbers can be so greatly lessened that old guaba and guamá trees which can not readily be removed, may safely be retained in the grove, if repeated applications of poisoned meat are made at intervals of a few days during dry weather. In practise, the use of ground meat and cyanide is too expensive and troublesome, and is not sufficiently effective to be whole-heartedly recommended to coffee growers generally. So far as known, it has never been used commercially, and, indeed the need for any artificial method of destroying the coffee shade tree ant was largely obviated, temporarily at least, by the hurricane of San Felipe, which blew down most of the older and larger shade trees in the coffee groves of the Island.

As the young shade trees grow larger however, they begin to harbor injurious numbers of hormiguilla, and eventually the problem of their economical control will again become pressing. Thus, at the same time that experiments were being conducted with thallium sul- 
fate against hormiga brava, parallel ones were started with this substance against the hormiguilla. A guamá tree, well infested with the hormiguilla was found only a short distance from the Sub-Station at Isabela, and preliminary experiments were commenced on it. The sulfate of thallium is very sparingly soluble in water, but it was hoped that a small amount of the finest powder mixed with ground fresh meat might dissolve. Judging by the results of the first experiment, none did so, for no apparent diminution was noted in the size of the colony after several weeks. When the poisoned meat was first placed on the tree, the ants swarmed about in their characteristic manner, devouring it greedily, but picking out and discarding any particle of the poison, minute to us but enormous to the ant, found mixed with meat. As the obvious cause of the failure of this experiment was that the poison was not in solution, a small amount of powder was cooked up with Campbell's mock turtle soup, and boiled until it was a thick paste. The ants were not the least bit deceived by the pseudo-meaty flavor of this mixture, and paid absolutely no attention to it.

Shortly after the ignominious failure of these experiments, $\mathrm{Mr}$. Behse suggested the use of one of the more soluble compounds of thallium, stating that, in his experience, vastly more than the amount of thallium acetate necessary to kill ants would dissolve readily in the amount of liquid present in fresh beef. For his own work he had not even considered this poison as being commercially practical, on account of its cost, but suggested that the small amount necessary for carrying out the preliminary experiments might be obtained from the Ore and Chemical Corp., 40 Rector St., New York City. Eventually, after some delay, for the poison had to be specially ordered and imported from the factory in Germany, an ample amount for experimentation was received thru the courtesy of this company. In the meantime, however, the experimenter had been transferred, to Río Piedras, in the near vicinity of which no hormiguilla infested trees are available for conducting experiments. After vainly examining numerous guaba and guamá trees, it was finally decided to use the historic jagüey tree in the Ciales valley near Manatí, for, in the course of the years which had elapsed since the close of the experiments with meat and cyanide on this tree, the colonies of hormiguilla had again become populous.

The first tentative application of a freshly prepared mixture of about a third of a pound of hamburger steak and two or three grams of thallium acetate on the trunk of this jagüey tree was made on August 4, 1932. The ants swarmed out to feed on the meat with 
their accustomed eagerness, and apparently were unaware that it had been mixed with a most powerful poison. To test their perception of the presence of the poison, an additional amount was dusted on the level portion of one bit of meat where they were feeding, and even while it was dissolving in the meat juices, the ants continued to eat.

At the time the application was made, the sun was shining brightly, and the trunk of the tree was dry, but a few hours later the sky became overcast, and during the afternoon and following night several showers fell. None was of sufficient size or duration to get more than a part of the trunk of the tree wet, and when examination was made the next day at noon, it was found that one effect of the rain had been to keep the meat from drying out, and many ants were still feeding on it. Some of the bits of meat had been fashioned into shelves, because the experimenter had become accustomed to moulding them into this shape when cyanide was mixed with the meat, and on these shelves, numerous dead ants were to be seen.

The second application of half a pound of steak and five ounces of thallium acetate was made three weeks later on this tree, in many cases on top of the dry remains of the meat applied previously, but also further around its enormous trunk. The ants came to the meat eagerly, but not in such large numbers on the part of the tree previously treated. A third application was made between two and three weeks later, ants still being numerous on all parts of the trunk. Ten days later a fourth application was made, and it was then for the first time noted that the ants were not especially numerous, and seemed not especially eager to eat the meat. The hurricane of San Ciprián occurred on September 26-27, 1932, and no opportunity to visit the jagüey tree was available until October 20th. Some of the larger branches of the tree, amounting to possibly a third or a fourth of its bulk, had been broken off by the hurricane, but the trunk was uninjured, and many of the larger branches and small twigs were intact. Very few hormiguilla were to be seen, and even when fresh, unpoisoned meat was placed on the trunk, no ants came to it. The remainder of half a pound of steak was poisoned and applied in the usual manner, mostly in new locations, but this brought out only a few ants. Of course, the hurricane by blowing away so many branches had considerably decreased the ant population of the tree, but this decrease would be only approximately in proportion to the amount of the branches so removed. By comparison with the number of ants present two months previously, a conservative estimate was that 
99 per cent of them were gone, and most of this was undoubtedly due to the thallium acetate.

The tree was later examined on November 30th, and while the trunk was still entirely free from ants, a considerable number could be found in the tips of twigs, in the part of the tree most distant from the trunk, where the poison had been applied. That the ants should have thus persisted in the tree indicates the difficult nature of the problem of hormiguilla control, for the ant population of a large tree consists, not of a single large colony, but of a large number of separate colonies, not sharply delimited, but each having communication only with its immediate neighbors. All the needs of the members of these colonies are supplied by resources close at hand, and apparently those inhabiting the twigs have little or no intercourse with those on the trunk. Nevertheless, the experiment indicates that commercial control of the hormiguilla: reducing the number of these ants present on the shade trees to such an extent that they do not overflow to the surrounding coffee trees, is now in sight.

How practical control by means of a proteid mixed with thallium acetate will be, how it will work out in practise in coffee groves, and how long such control will be effective, are points yet to be determined. Experiments were promptly started in coffee groves, but the Station at Río Piedras is most unfortunately located for initiating, continuing and observing such work in coffee groves, and the actual operation has necessarily been turned over to the Agents of the Extension Service who are located in coffee regions.

The three most important factors in determining the adoption of any method of insect control are: (1) non-injuriousness to host, (2) effectiveness, and (3) cost. In thus analyzing the value of the thallium acetate meat bait mixture for hormiguilla control, it should be noted that thallium is poisonous to vegetation as well as to animal life, but in the small amounts used, no effect at all has been noted either on the trees on which it was applied, or on the surrounding vegetation. Effectiveness appears to be close to perfection, altho it is yet much too early to say anything about permanence. The third factor-cost-is unquestionably high in the present stage of development of this method of control, but may be very considerably reduced as cheaper and more desirable substitutes for fresh hamburger steak, and simpler methods of application are devised. The poison itself is admitted expensive, but such minute quantities are needed that it is not the major item in total cost. Indeed, in these experiments, the steak at 18 cents a pound was more 
expensive than the thallium that was mixed with it. Thallium sulfate is now extensively used in California and Hawaii in rodent control, and in south Texas in ant control, and it is only a third cheaper than the acetate. The present price of thallium acetate is something under $\$ 11$ per pound in hundred pound lots, or a little over two cents a gram. Up to the present there has been no commercial demand for it, but if other uses for it are developed, this price may be somewhat reduced. It is quite possible that even smaller amounts per treatment would be effective if the poison could be more thoroly mixed with the bait. A uniform mixture would be ensured by the use of a meat jelly, semisolid at ordinary temperatures, but liquid at the higher temperature at which the solution of the poison is added. By the addition of other substances, the jelly could be given other desirable qualities: greater adhesiveness and less tendency to dry out rapidly after application, or to spoil if not used immediately.

\section{SUMMARY}

1. Under local conditions, experiments have indicated little value for thallium compounds and mixtures against the hormiga brava, Solenopsis geminata F., out-of-doors. In-doors, the thallium sulfate syrup has been just as uniformly successful as out-of-doors it is a failure. An emulsion of crude carbolic acid, either alone or mixed with kerosene emulsion or the engine oil emulsion sprays used for scale control, is still the cheapest and most effective insecticide to use against this ant in citrus groves, pineapple plantings and vegetable gardens.

2. Against the hormiguilla, Myrmelachista ambigua ramulorum Wheeler, a bait consisting of ground meat and thallium acetate is very effective, and gives promise of being adopted commercially when cheaper and simpler methods of application are devised.

\section{BIBLIOGRAPHY}

1. Barber, E. R., "The Argentine Ant: Distribution and Control in the United States". U. S. Dept. Agr. Bull. 377, pp. 23, fig. 4, table 1. Washington, August 18, 1916.

2. Wheeler, Wm. IM., "The Ants of Porto Rico and the Virgin Iślands". Bull. Amer. Mus. Nat. Hist., 24, (Art. 6) : 117-150, fig. 4, pl. 2. New York, 1908.

3. Tower, W. V., "Control of the Brown Ant (Solenopsis geminata, F $c \cdot b$.) and the Mealy Bug (Pseudococcus citri, Risso) in 
Pineapple Plantations. Porto Rico Agr. Expt. Sta. Circ. No. 7, pp. 3. (Mayagüez, 1908).

4. Tower, W. V., "'Insects Injurious to Citrus Fruits and Methods for Combating Them'. Porto Rico Agr. Expt. Sta. Bull. No. 10, pp. 35, pl. 3, many refs. Washington, May 8, 1911.

5. Cotton, R. T. \& Ellington, G. W., "A Simple and Effective Ant Trap for Household Use', Jour Ec. Ent., Vol. 23 (2), 463464, fig. 1. April 1930.

6. Clark, S. W., "The Control of Fire Ants in the Lower Río Grande Valley', Texas Agr. Expt. Sta. Bull. 435, pp. 12, fig. 4, tables 4, ref. 5. November, 1931. 